[Agr. Biol. Chem., Vol. 36, No. 6, p. 917 923, 1972]

\title{
Gas Chromatographic Separation and Determination of Optical Isomers of Chrysanthemic Acid ${ }^{+13}$
}

\author{
By Atsushi Murano \\ Takarazuka Research Laboratory, Sumitomo Chemical Co., Lid.†1 \\ Received September 16, 1971
}

\begin{abstract}
Separation and determination of the optical isomers of chrysanthemic acid has been carried out by gas chromatography. The diastereoisomeric esters of chrysanthemic acid with $l$-menthol were separated on a column of $20 \%$ QF-l coated on Chromosorb W. d-trans, l-trans and dl-cis Chrysanthemic acids were resolved but $d$-cis and $l$-cis acids were not separatable from one another on any column tested. These isomers of chrysanthemic acid were not isomerized during esterification and gas chromatographic operation, and their ratios were determined from their peak area ratios. The l-bornyl esters of the isomers of chrysanthemic acid were not so easily separatable as the l-menthyl esters.
\end{abstract}

Chrysanthemic acid has two geometrical isomers and two optical ones, that is, four isomers in all; $d$-trans, l-trans, $d$-cis and l-cis forms. As already known, pyrethrin I, one of the naturally occurring insecticides in pyrethrum extracts, is an ester of $d$-trans-chrysanthemic acid. Some of the synthetic esters of chrysanthemic acid have high toxicity to many kinds of insect and among them allethrin and phthalthrin are manufactured in this country. Isomers of these pyrethroidal esters have various degrees of toxicity to insects depending upon the conformations of chrysanthemoyl groups in their molecules. Many trans isomers of the acid components of the esters have higher toxicity than the cis isomers of the same esters, and $d$-conformations are more effective than $l$-conformations. Accordingly, the $d$-trans isomer of allethrin bas the highest toxicity and is about a hundred times more toxic than the $l$-cis isomer. ${ }^{1,2)}$ Hence, it is meaningful to determine these isomers of chrysanthemic acid, especially d-trans-chrys-

\footnotetext{
†1 Analytical studies on pesticides and related compounds. XIII. The previous paper, A. Murano and N. Nagase, Agr. Biol. Chem., 36, 101 (1972).

†2 4-2-1 Takatsukasa, Takarazuka-shi, Hyōgo-ken.
}

anthemic acid. Determination of the trans and cis ratio of chrysanthemic acid by gas chromatography (GG) has been reported, ${ }^{31}$ but attempts have not been made to separate the optical isomers.

In conclusion $\mathrm{GC}$ is a valuable tool for the separation of these optical isomers. In principle two approaches are possible for this purpose: 1) Separation of the enanthiomers on an optically active stationary phase; 2) Conversion of the enanthiomers to the diastereoisomers prior to analysis and chromatography on an optically inactive phase. The latter method was tried to separate the isomers of chrysanthemic acid, and the optical isomers of trans-chrysanthemic acid were separated and determined by $G G$ in the form of l-menthyl esters of highly optical purity. The $l$-bornyl esters of these isomers of chrysanthemic acid were not so easily separatable as the $l$-menthyl esters.

\section{RE $\backslash G E N T S$ AND MATERIALS}

$$
\begin{aligned}
& \text { d-trans-Chrysanthemic acid. Viscous liquid. } n_{\mathrm{D}}^{25} \\
& 1.4748,[\alpha]_{\mathrm{D}}^{25}+20.08^{25} \text { (neat), }[\alpha]_{\mathrm{D}}^{25}+26.80^{\circ}(c=5.00 \\
& \text { chloroform). }
\end{aligned}
$$




\section{l-trans-Chrysanthemic acid.}

Viscous liquid. $n_{\mathrm{D}}^{25} 1.4749,[\alpha]_{\mathrm{D}}^{25}-20.13^{\circ}$ (neat).

d-cis-Chrysanthemic acid

White crystal. $\operatorname{mp} 41.5 \sim 42.5^{\circ} \mathrm{C},[\alpha]_{\mathrm{D}}^{25}+41.15^{\circ}(c=$ 5.00 , ethanol $),[\alpha]_{\mathrm{D}}^{25}+87.90^{\circ}(c=5.00$, chloroform $)$.

l-cis-Chrysanthemic acid

White crystal. mp $41.5 \sim 42.5^{\circ} \mathrm{C},[\alpha]_{\mathrm{D}}^{25}-40.96^{\circ}(c=$ 5.00 , ethanol).

\section{dl-trans-Chrysanthemic acid}

White crystal. mp $54 \sim 55^{\circ} \mathrm{C}$. This was used as a standard for the quantitative determination of chrysanthemic acid.

dl-cis-Chrysanthemic acid. White crystal. mp 114 $115.5^{\circ} \mathrm{C}$.

l-Menthol. Available from Wako Pure Chemical Industries, Ltd. $\operatorname{mp} 41 \sim 42.5^{\circ} \mathrm{C} . \quad[\alpha]_{\mathrm{D}}^{25}-50.23^{\circ}(c=$ 4.90, ethanol).

l-Borneol. Available from Aldrich Chemical Co. INC., Milwaukee, Wis., USA. mp $206^{\circ} \mathrm{C},[\alpha]_{\mathrm{D}}^{25}$ $-36.38^{\circ}(c=4.94$, ethanol).

Toluene and pyridine. JIS guaranteed reagents were dried on sodium metal and potassium hydroxide, respectively.

Pyridine, thionyl chloride and l-menthol solutions. Twenty $\mathrm{mg}$ of pyridine, $84 \mathrm{mg}$ of thionyl chloride and $330 \mathrm{mg}$ of $l$-menthol were contained in $1 \mathrm{ml}$ of toluene.

\section{EXPERIMENTAL}

d-trans-Chrysanthemoyl chloride. d-trans-Chrysanthemic acid $(33.6 \mathrm{~g}, 0.2 \mathrm{M})$ and thionyl chloride $(30.7 \mathrm{~g}$, $0.22 \mathrm{M}$ ) were dissolved in $70 \mathrm{ml}$ of petroleum benzin. The mixture was gradually heated and then refuxed for $2.5 \mathrm{hr}$ on a mantle heater. Excess thionyl chloride and petroleum benzin were removed and the residue was distilled under a reduced pressure. $34.8 \mathrm{~g}$ of a liquid was obtained $\left(930^{\circ}\right.$ yield), bp $66.5 \sim 68^{\circ} \mathrm{C}$ / $2 \mathrm{mmHg}, \quad[\alpha]_{\mathrm{I}}^{25}-17.17^{\circ}$ (neat).

l-Menthyl d-trans-chrysanthemic acid. l-Menthol $(3.91 \mathrm{~g}, 0.025 \mathrm{M})$ and $d$-trans-chrysanthemoyl chloride $(5.13 \mathrm{~g}, 0.028 \mathrm{M})$ were dissolved in $40 \mathrm{ml}$ of dry benzene. Pyridine in benzene $(10 \mathrm{ml}, 0.028 \mathrm{M})$ was added dropwise and the mixture was stirred for $2 \mathrm{hr}$ at room temperature. The hydrochloride salt of pyridine was precipitated. The reaction mixture was washed with $10 \%$ hydrochloric acid, $5 \%$ aqueous sodium bicarbonate and saturated sodium chloride solution. The solvent was removed and a viscous liquid $(8.4 \mathrm{~g})$ was obtained. It was dissolved in $n$ hexane and applied to a chromatographic column which had been packed with 100 200 mesh silica gel (Kanto Chemical Co., Ltd., for chromatographic use) and developed with $n$-hexane-tetrahydrofuran $(100: 3)$ to remove chrysanthemumic anhydride. The eluted ester was distilled under reduced pressure and it was used as a standard for the determination of l-menthyl d-trans-chrysanthemate. $\mathrm{Bp} 132^{\circ} \mathrm{C} / 0.25 \mathrm{~mm}$ $\mathrm{Hg}, n_{\mathrm{D}}^{25} 1.4737,[\alpha]_{\mathrm{D}}^{25}-51.38^{\circ}(c=5.12$, ethanol). Anal. Found: $\mathrm{C}, 78.24 ; \mathrm{H}, 11.27$; Calcd. for $\mathrm{C}_{20} \mathrm{H}_{34} \mathrm{O}_{2}$ : C, $78.38 ; \mathrm{H}, 11.18^{\circ} \circ$. IR $\nu_{\mathrm{max}}^{\mathrm{Film}} \mathrm{cm}:-2960,2900,1722$, $1453,1420,1380,1315,1280,1230,1193,1165,1113$, $1093,1080,1060,1037,1020,986,950,911,855$.

l-Menthyl dl-cis,trans-chrysanthemate. It was synthesized from $l$-menthol and $d l-c i s, t r n s$-chrysanthemoyl chloride in the same manner as l-menthyl d-transchrysanthemate and distilled in vacuo. $\mathrm{Bp} 124^{\circ} \mathrm{C} / 0.3 \mathrm{~mm}$ $\mathrm{Hg}, n_{\mathrm{D}}^{25} 1.4733,[\alpha]_{\mathrm{D}}^{25}-48.28^{\circ}(c=4.06$, ethanol $)$.

l-Bornyl dl-cis,trans-chrysanthemate. It was synthesized from $l$-borneol and $d l$-cis,trans-chrysanthemoyl chloride in the same manner as l-menthyl d-transchrysanthemate and distilled in vacuo. Bp $153^{\circ} \mathrm{C} / 0.5$ $\mathrm{mm} \mathrm{Hg},[\alpha]_{\mathrm{D}}^{25}-26.39^{\circ}(c=5.24$, ethanol).

Di-l-menthyl sulfite. Pyridine $(0.2 \mathrm{~g})$, thionyl chloride $(0.84 \mathrm{~g})$ and $l$-menthol $(3 \mathrm{~g})$ were dissolved in toluene in this order. The mixture was allowed to stand for $2 \mathrm{hr}$ at room temperature, washed with $10 \%$ hydrochloric acid and deionized water, and toluene was removed. The residue was purified by chromatography, utilizing silica gel as an adsorbent and chloroform as a developing solvent. Mp 49 $51^{\circ} \mathrm{C},[\alpha]_{\mathrm{D}}^{25}-81.53^{\circ}(c=4.35$, ethanol), Anal. Found: $\mathrm{C}, 66.91 ; \mathrm{H}, 10.69 ; \mathrm{S}, 8.85$; Calcd. for $\mathrm{C}_{20} \mathrm{H}_{38} \mathrm{O}_{3} \mathrm{~S}$ : C, $66.97, \mathrm{H}, 10.69 ; \mathrm{S}, 8.95 \%$. IR $\nu_{\mathrm{max}}^{\mathrm{Nujol}} \mathrm{cm}:-1460$, $1388,1372,1190,1003,960,940,905,850,750$. The gas-chromatographic retention time of $d i$-l-menthyl sulfite was $9.5 \mathrm{~min}$ under the following conditions: column, $10 \%$ polyethyleneglycol sebacate polyester coated on $60 \sim 80$ mesh and acid-washed chromosorb $\mathrm{W}(1 \mathrm{~m} \times 3 \mathrm{~mm} \phi)$; column temperature, $200^{\circ} \mathrm{C}$; carrier 
gas nitrogen $20 \mathrm{ml} / \mathrm{min}$; detector, FID.

Gas chromatography. A Hitachi-Perkin Elmer model F-6 gas chromatograph and A Shimadzu model GC$5 \mathrm{~A}$ each equipped with a flame ionization detector were employed for packed and Golay columns (Hitachi Co.), respectively. The column packings were $60 \sim$ 80 mesh, acid-washed and silanized Chromosorb W (Johns Manville Int. Co.) coated with various stationary liquid phases.

Measurement of optical rotation. The optical rotation of $50^{\circ}$ chrysanthemic acid in chloroform solution was measured at $589 \mathrm{~m} \mu$ in a $10 \mathrm{~cm}$ quartz cell with a Yanagimoto automatic polarimeter OR-50.

Determination of chrysanthemic acid. The total content of chrysanthemic acid was determined by GC according to the method of Miyamoto et al., 3 itilizing 10 \% polypropyleneglycol sebacate polyester as a stationary liquid phase and dimethylphthalate as an internal standard.

Esterification of chrysanthemic acid with l-menthol. One ml of a thionyl chloride solution was added to $1 \mathrm{ml}$ of a pyridine solution and the mixture was stirred for $20 \mathrm{~min}$ at room temperature or in an ice bath, to which $1 \mathrm{ml}$ of d-trans-chrysanthemic acid in toluene $(30 \mathrm{mg})$ and a $l$-menthol solution were added. One $\mathrm{ml}$ of dimethylphthalate $(50 \mathrm{mg}$ ) was added to the reaction mixture as an internal standard and a chromatogram was obtained under the following GC conditions: column, an $1 \mathrm{~m}$ long glass column with $3 \mathrm{~mm}$ inner diameter packed with 10,0 poly. propyleneglycol sebacate polyester, column temperature, $150^{\circ} \mathrm{C}$, carrier gas, nitrogen $20 \mathrm{ml} / \mathrm{min}$. The resulting $l$-menthyl d-trans-chrysanthemate was determined from a calibration curve. The chromatogram is shown in Fig. 1.

Determination of optical isomers of chrysanthemic acid. To $30 \mathrm{mg}$ of chrysanthemic acid, $1 \mathrm{mI}$ of pyridine solution, $1 \mathrm{ml}$ of thionyl chloride solution and $1 \mathrm{ml}$ of $l$-menthol solution were added in these order and the mixture was heated on a boiling water bath for $20 \mathrm{~min}$. An aliquot $(0.8 \mu)$ of the supernatant was injected and a chromatogram was obtained under the GC operational condition shown in Table I. Isomer ratios were determined from their peak area ratios.

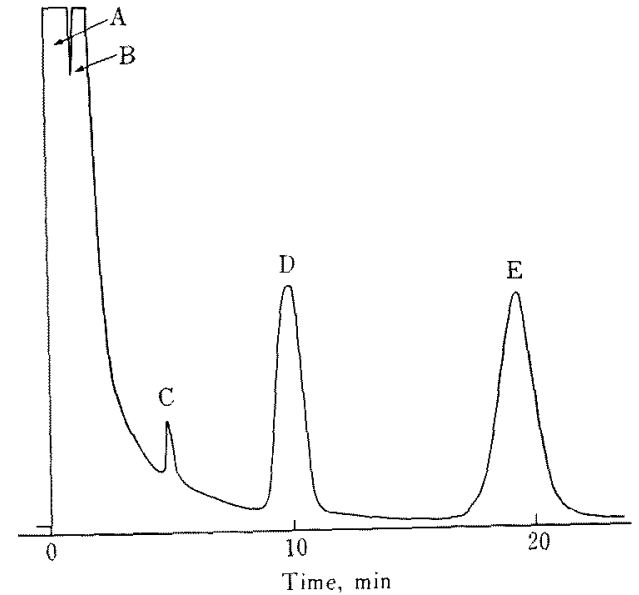

FIG. 1. Gas Chromatogram of l-Menthyl Chrysanthemate.

Column: 10: Polypropyleneglycol sebacate polyester, $1 \mathrm{~m} \times 3 \mathrm{~mm} \phi$, Column temperature: $150^{\circ} \mathrm{C}$, Carrier: nitrogen $20 \mathrm{ml} / \mathrm{min}$.

$A$ : toluene (solvent); B: l-menthol, C: chrysanthemic acid; D: dimethyl phthalate (IS); E: $l$ menthyl chrysanthemate.

\section{Table 1. Operational Condition of GC For ANALYSIS OF OPTICAL ISOMERS OF Chrysanthemic ACID}

\begin{tabular}{|c|c|}
\hline Apparatus: & Shimadzu GC-5A with FID \\
\hline Column: & Glass, $2 \mathrm{~m} \times 3 \mathrm{~mm} \phi$ \\
\hline Packing: & $\begin{array}{l}20, Q F-1 \text { coated on } 60 \sim 80 \text { mesh, acid- } \\
\text { washed and silanized Chromosorb } W\end{array}$ \\
\hline Carrier: & Helium $50 \mathrm{~m} / \mathrm{min}$ \\
\hline $\begin{array}{l}\text { FID gas flow } \\
\text { rate: }\end{array}$ & Hydrogen $40 \mathrm{ml} / \mathrm{min}$; Air $0.9 \mathrm{liter} / \mathrm{min}$ \\
\hline Temperature: & Column $120^{\circ} \mathrm{C}$, injection port $150^{\circ} \mathrm{C}$ \\
\hline $\begin{array}{l}\text { Sensitivity } \\
\text { and range: }\end{array}$ & $10^{2} \times 16$ \\
\hline Chart speed: & $10 \mathrm{~mm} / \mathrm{min}$ \\
\hline $\begin{array}{l}\text { Peak } \\
\text { calculation: }\end{array}$ & Triangulation method \\
\hline
\end{tabular}

\section{RESULTS AND DISCUSSIONS}

1) Gas chromatography of chrysanthemic acid as l-menthyl and l-bornyl ester derivatives

Various stationary liquid phases of packed and Golay columns were tested for the separa- 
Table II. Stationary Liquid Phases InvestiGATED FOR SEPARATION OF DIASTEREOISOMER ESTERS OF CHRYSANTHEMIC ACID

\begin{tabular}{|c|c|c|c|}
\hline & & Column size & Column \\
\hline Liquid phase & $\underset{\%}{\text { Content }}$ & $\begin{array}{cc}\text { Inner } & \text { length } \\
\text { diameter } & \mathrm{m} \\
\mathrm{mm} & \mathrm{m}\end{array}$ & $\begin{array}{c}\text { tempera- } \\
\text { ture } \\
{ }^{\mathrm{C}}\end{array}$ \\
\hline
\end{tabular}

\begin{tabular}{lcccc}
\hline Packed columns & & & & \\
QF-1 & 2 & 3 & 2 & 120 \\
SE-30 & 5 & 3 & 1 & 140 \\
XE-60 & 2 & 3 & 1 & 120 \\
DEGS & 2 & 3 & 1 & 100 \\
LAC-2R-446 & 2 & 3 & 1 & 100 \\
Polyester FA & 5 & 3 & 1 & 130 \\
$\begin{array}{l}\text { Polypropylene- } \\
\quad \text { glycol sebacate }\end{array}$ & 5 & 3 & 1.5 & 180 \\
$\quad$ polyester & & & & \\
DC-550 & 3 & 3 & 1.5 & 150 \\
OV-17 & 3 & 1 & 150 \\
PEG-20M & 10 & 3 & 0.75 & 150 \\
Golay columns & & & & \\
FS-1265 & & 0.25 & 90 & 180 \\
SE-30 & & 0.5 & 90 & 180 \\
Apiezon grease L & & 0.25 & 45 & 190 \\
DBS-90 & & 0.25 & 90 & 195 \\
\hline
\end{tabular}

tion of the optical isomers of chrysanthemic acid as $l$-menthyl and $l$-bornyl ester derivatives. The investigated columns are listed in Table II and some of the chromatograms are shown in Figs. 2 5.

As for packed columns, 2\% QF-1 (Fig. 2) separated completely the $l$-menthyl esters of $d$-trans, $l$-trans and $d l$-cis chrysanthemic acids, but it did not separate those of $d$ - and $l$-cis isomers, whereas the $l$-bornyl ester derivatives of $d$ - and l-trans chrysanthemic acids were not separatable. On the column of $5 \% \mathrm{SE}$ 30 (Fig. 3), the $d$-trans isomer of the $l$-menthyl ester tended to be separated from the other isomers but the cis isomer of the l-bornyl ester appeared at the shoulder of the trans one. On $5 \%$ XE-60, the d-trans isomer of the $l$-menthyl ester was resolved from the other isomers but that of the l-bornyl ester was not. With other liquid phases such as PEG-20M, diethyleneglycol succinate polyester (DEGS), polyethyleneglycol sebacate polyester, polyester FA, DC-550 and OV-17, separation of the $l$-menthyl esters was not complete and the l-bornyl esters gave the same retention time.

On the other hand, Golay columns were

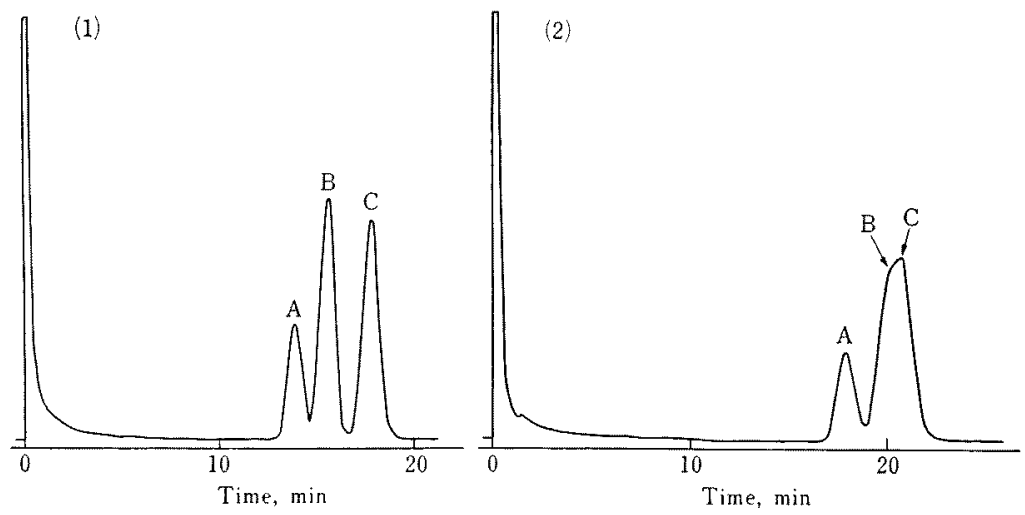

FIG. 2. Gas Chromatogram of Diastereoisomer Esters of Chrysanthemic Acid on a Column Packed with $2 \%$ QF-1.

(1) l-Menthyl ester. (2) l-Bornyl ester.

$\mathrm{A}: d-+$-cis, B: l-trans, $\mathrm{C}$ : d-trans. 


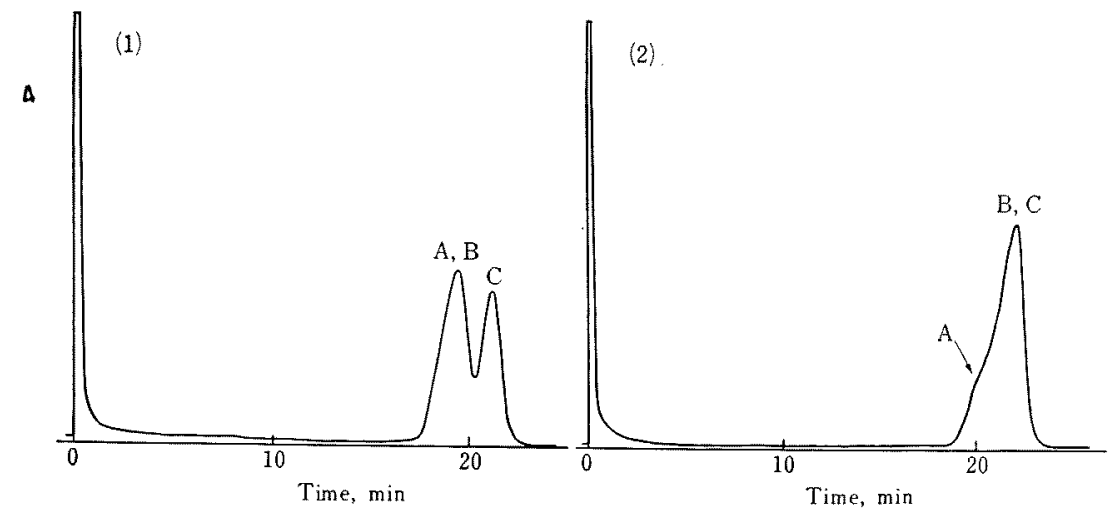

FIG. 3. Gas Chromatogram of Diastereoisomer Esters of Chrysanthemic Acid on a Column Packed with $50_{0}$ SE-30.

(1) l-Menthyl ester. (2) l-Bornyl ester.

A: d-+l-cis, B: l-trans, C: d-trans.
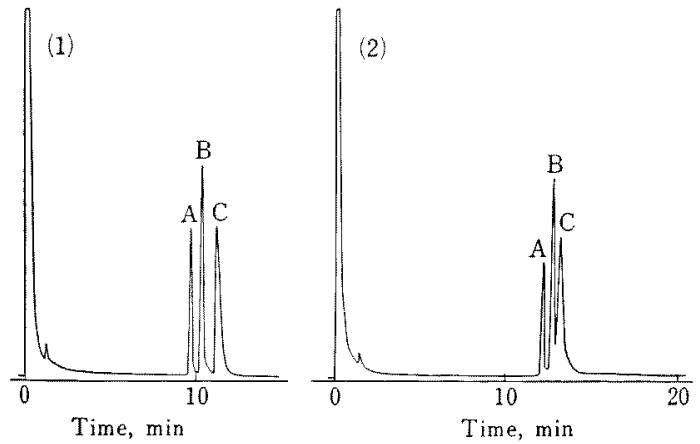

FIG. 4. Gas Chromatogram of Diastereoisomer Esters of Chrysanthemic Acid on a Golay Column Coated with Fluorinated Silicone Oil FS-1265.
(1) $l$-Menthyl ester.
(2) l-Bornyl ester.
A: d-t-l-cis, B: l-trans, $C$ :d-trans.

useful for the separation of the diastereoisomers of chrysanthemic acid. On FS-1265 (QF-1, Fig. 4), the d-trans, l-trans and $d l$-cis forms of the $l$-menthyl esters were separated from each other as well as on the packed column, but those of the $l$-bornyl esters were not so easily separatable. Resolution of the diastereoisomer esters of chrysanthemic acid was not achieved on SE-30 (Fig. 5), apiezon grease $\mathrm{L}$ and BDS-90.
As described above, a trifluoropropyl methyl silicone, $Q F-1$, was the most suitable as the stationary liquid phase. The $l$-menthyl diastereoisomers of chrysanthemic acid were separatable more easily than the l-bornyl esters. These isomers were not so easily separated from each other on such a packed column as Golay column, but a packed column with $2 \% \mathrm{QF}-1$ was chosen for the determination of the enantiomers, because the chromatographic peaks of the Golay column were tailed and hence it was difficult to calculate peak areas accurately. The $d$ - and $l$ cis isomers were not separated from each other on any column investigated.

\section{2) Esterification of chrysanthemic acid with $l$ - menthol}

There are various methods for the esterification of carboxylic acids. A simple and practical method was investigated by utilizing thionyl chloride, and the optimum condition for the esterification of chrysanthemic acid with $l$-menthol was determined.

As the molar ratio of thionyl chloride to $d$-trans-chrysanthemic acid increased, the formation of the ester increased, and at room temperature it reached a maximum when 


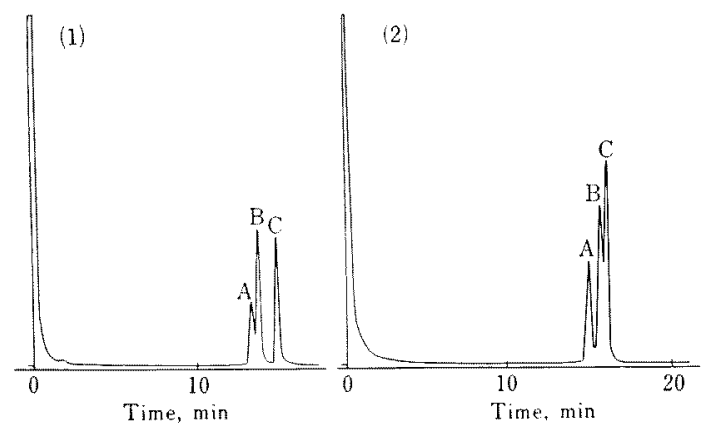

FIg. 5. Gas Chromatogram of Diastereoisomer Esters of Chrysanthemic Acid on a Golay Column Coated with SE-30.
(1) l-Menthyl ester,
(2) l-Bornyl ester.

A: d-t-l-cis, B: l-trans, $\mathrm{C}: d$-trans.

the molar ratio of thionyl chloride to chrysanthemic acid was four as shown in Fig. 6. Under cooling in an ice bath, the reaction proceeded more slowly; when chrysanthemic acid and thionyl chloride were dissolved in benzene, refluxed and thereafter pyridine and $l$-menthol were added, only $80 \%$ of chrysanthemic acid was esterified, even if eight times the molar quantity of thionyl chloride was used.

Figure 7 shows the relationship between the molar ratio of pyridine to chrysanthemic acid and the rate of esterification of chrysanthemic acid. When no pyridine was used, less than 50 per cent of chrysanthemic acid was esterified and when the molar quantity of pyridine was 0.25 to 2 times, the formation of the ester increased as the quantity of pyridine increased. But, when the molar ratio was more than 2 times, the esterification of chrysanthemic acid decreased gradually as the quantity of pyridine increased. It was suggested that pyridine acted as a catalyst and less than an equimolar amount of pyridine was sufficient for the quantitative esterification of chrysanthemic acid with $l$-menthol.

Figure 8 indicates that 10 times molar quantity of $l$-menthol was required; excess thionyl chloride reacted with $l$-menthol to

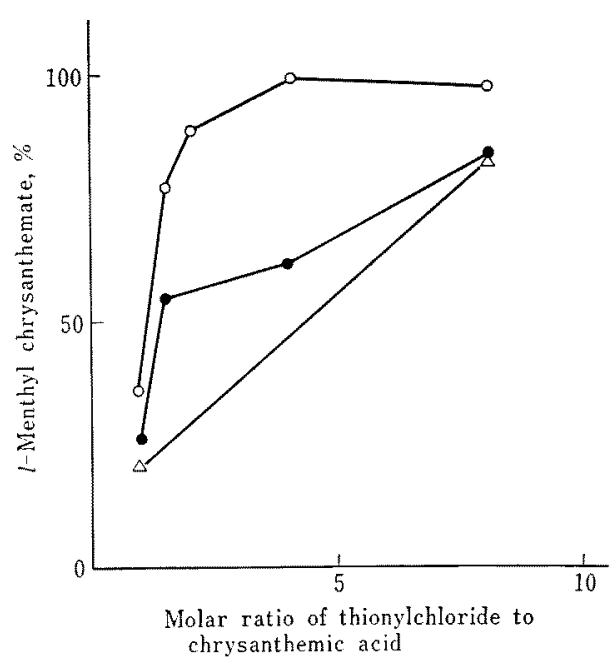

FIG. 6. Effect of Thionylchloride on Esterification of Chrysanthemic Acid.

O-O: Room temperature.

- Cooling in an ice bath.

$\triangle-\triangle:$ Chrysanthemic acid and thionylchloride dissolved in dried benzene were refluxed for $2 \mathrm{hr}$ and then the esterification was carried out with $l$ menthol.

form di-l-menthyl sulfite as evidenced by gas chromatography.

As mentioned above, the esterification of

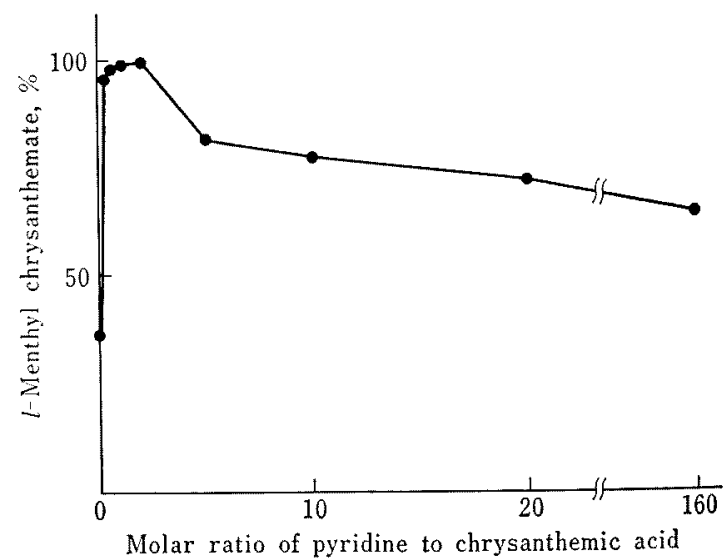

FIG. 7. Effect of Pyridine on Esterification of Chrysanthemic Acid. 


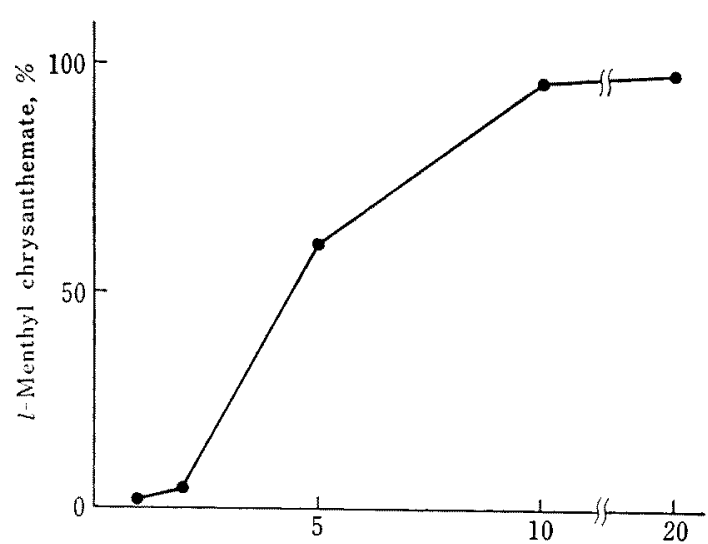

Nolar ratio of $l$-menthol to chrysanthemic acid

FIG. 8. Effect of $l$-Menthol on Esterification of Chrysanthemic Acid.

chrysanthemic acid proceeded best when the molar ratio of thionyl chloride, pyridine and $l$-menthol to the acid were $4,1.5$ and 10 , respectively.

\section{3) Analytical results of chrysanthemic acid}

Table III shows the analytical results of mixtures containing the isomers of chrysanthemic acid. The isomers of chrysanthemic acid were not converted to each other and their ratios were found to be accurately determined by their peak area ratios. Table IV indicates the analytical results of some technical samples of chrysanthemic acid synthesized in this laboratory.

Acknowledgement. The author wishes to express his thanks to Dr. Tsugio Takeuchi, Professor of Nagoya University, and Dr. Junshi Miyamoto for their helpful suggestions in the preparation of this paper. He also wishes to thank Sumitomo Chemical Co., Ltd., for the permission to publish this work. $\mathrm{He}$ is no less indebted to $\mathrm{Mr}$. Toshinori Kosaka for his skilled technical assistance.
Table III. Analytical Results of Mixtures Containing Isomers of CHRYSANTHEMIC ACID

\begin{tabular}{|c|c|c|c|c|c|}
\hline \multicolumn{5}{|c|}{ Isomers ratio, 8} & \\
\hline \multicolumn{3}{|c|}{ Theoretical } & \multicolumn{3}{|c|}{ Found } \\
\hline$d$-trans & l-trans & $d l-c i s$ & $d$-trans & l-trans & $d-+l$-cis \\
\hline 100 & - & - & 100 & 0 & 0 \\
\hline - & 100 & - & 0 & 100 & 0 \\
\hline- & - & $100^{a}$ & 0 & 0 & 100 \\
\hline 90.0 & 10.0 & - & 90.9 & 9.1 & 0 \\
\hline 80.0 & 20.0 & - & 80.3 & 19.7 & 0 \\
\hline 70.1 & 29.9 & - & 70.0 & 30.0 & 0 \\
\hline 20.0 & 80.0 & - & 20.4 & 79.6 & 0 \\
\hline 90.0 & - & 10.0 & 90.1 & 0 & 9.9 \\
\hline 80.0 & - & 20.0 & 79.9 & 0 & 20.1 \\
\hline 50.0 & - & 50.0 & 49.8 & 0 & 50.2 \\
\hline 20.0 & - & 80.0 & 19.9 & 0 & 80.1 \\
\hline 80.0 & 10.0 & 10.0 & 79.8 & 11.0 & 9.2 \\
\hline 60.0 & 30.0 & 10.0 & 60.4 & 30.1 & 9.5 \\
\hline 60.0 & 10.0 & 30.0 & 59.5 & 10.6 & 29.9 \\
\hline 50.0 & 25.0 & 25.0 & 50.0 & 25.6 & 24.4 \\
\hline
\end{tabular}

a) Neither $d$ - nor l-cis-chrysanthemic acid was converted to the trans isomers.

TABLE IV. ANALYTICAL RESUlts OF Chrysanthemic ACID

\begin{tabular}{|c|c|c|c|c|c|}
\hline \multirow{2}{*}{ No. } & \multirow{2}{*}{$\begin{array}{c}\text { Content, } \\
90\end{array}$} & \multicolumn{3}{|c|}{ Isomers ratio, } & \multirow{2}{*}{$\begin{array}{c}{[\alpha]_{\mathrm{D}}^{25}} \\
\left(\mathrm{CHCl} l_{3}\right)\end{array}$} \\
\hline & & $d$-trans & $l$-trans & $d-+l$-cis & \\
\hline $\mathrm{A}$ & 78.8 & 57.3 & 42.4 & 0.3 & +3.67 \\
\hline B & 99.5 & 83.1 & 16.6 & 0.3 & +17.69 \\
\hline $\mathrm{C}$ & 93.9 & 65.2 & 25.5 & 9.3 & +43.80 \\
\hline $\mathrm{D}$ & 93.7 & 63.9 & 16.4 & 19.7 & +59.20 \\
\hline $\mathrm{E}$ & 94.0 & 56.9 & 14.9 & 28.2 & +25.30 \\
\hline $\left.\mathrm{F}^{a}\right)$ & 97.0 & 35.0 & 35.1 & 30.0 & - \\
\hline
\end{tabular}

a) Racemic.

\section{REFERENCES}

1) W. A. Gersdorf, J. Econ. Entmol., 40,878 (1947).

2) M. Elliott, J. Sci. Food Agric., 5, 505 (1954).

3) J. Miyamoto, Y. Sato and K. Awano, Agr. Biol. Chem., 33, 1095 (1969). 